\title{
Influence of the properties of road pavement structures and materials on service indices of wearing courses
}

\author{
Matas Bulevičiuss $^{\mathrm{a}, \mathrm{b}}$, Kazys Petkevičius ${ }^{\mathrm{a}}$, Andrius Baltrušaitis ${ }^{\mathrm{b}}$ \\ ${ }^{a}$ Vilnius Gediminas Technical University, Sauletekio al. 11, LT-10223 Vilnius, Lithuania \\ ${ }^{b}$ Joint Stck Company "Problematika", Galvès g. 2, LT-02241 Vilnius, Lithuania
}

\begin{abstract}
The rapid growth of heavy traffic and increase in standard axle load has prompted scientists to research new and durable road construction materials and compounds for use in pavement structural layers. The International Roughness Index IRI and rut depth are one of the operating indices that measure the condition and lifetime of pavement structures. It is known that the quality properties of materials and pavement structural layers have a direct influence on the durability and life time of wearing courses. This article presents investigations of different quality indices of road construction materials including the service indices IRI and rut depth of wearing courses. The article will also describe and interpret how the properties and qualities of road construction materials influence and cause variation in service indices of wearing courses.
\end{abstract}

Keywords: International roughness index; rut depth; service indices; roughness; pavement structural layers; wearing courses.

\section{Introduction}

Research by the Lithuanian scientists showed that Lithuanian motor roads by their service and strength indices (pavement roughness, rutting, pavement structural strength, etc.) are not able to withstand the continuously growing axle loads [1-3]. Therefore, after the year 1990, when the volume of improvement, repair and strengthening works decreased, condition of road pavements started to worsen, the amount of potholes and ruts increased and the structural pavement strength (according to the Relative Strength Index SNC) started to decrease.

Many foreign and Lithuanian scientists came to a conclusion that heavy vehicles make not only negative impact on pavement evenness but also press out pavement ruts, and such defects reduce traffic safety [4-6].

Some scientists state that the newly laid pavement structure exposed to a continuous impact of heavy vehicles shall be strengthened anew after seven-eight years. The research studies by Lithuanian scientists indicate that the new pavement structures would serve for the projected time if more expensive technologies of pavement strengthening are applied, new materials are used and thicker pavement structural layers are laid. The studies have determined that a proper use of Pavement Management System (PMS) allows saving about 20\% of funds allocated to road maintenance and repair [7], [8].

In the West European countries, USA and other post-industrial countries the special systems have been created to manage road pavement condition. The best-known are HDM and MEPDG. Those systems allow predicting pavement condition parameters taking into consideration the modulus of elasticity of pavement structural layers, their thickness, material strength, climatic and environmental conditions, traffic composition, traffic volume, etc [9-12].

The problem of road pavement rutting is witnessed worldwide and it keeps persisting [13]. Minimal (due to shortage in funds) strengthening of road pavement structure took place in the middle of the last decade on an international Via Baltica highway A5 and in IXB transport corridor. No need of repairs for at least another 10 to 12 years has been expected after the road pavement structure (RPS) strengthening however, rapid increase in heavy duty vehicle traffic necessitated repetitive road strengthening after a lapse of seven to eight years [14]. Application of more expensive technologies for the strengthening of road pavement structure (RPS) and the use of new materials and laying of thicker RPS courses should be relied on to safeguard the design duration of the newly strengthened sections of road pavement [1-3].

Corresponding author: Matas Bulevičius. E-mail address: matas.bulevicius@problematika.lt

http://dx.doi.org/10.3846/enviro.2014.148

(C) 2014 The Authors. Published by VGTU Press. This is an open-access article distributed under the terms of the Creative Commons Attribution License, which permits unrestricted use, distribution, and reproduction in any medium, provided the original author and source are credited. 
Roughness of the road asphalt concrete pavement is dependent on the type, thickness and condition of bases. Furthermore, quality indices of the materials used have a decisive impact as well. The pavement roughness and rutting depends on the composition of asphalt concrete, its structure and physical and mechanical parameters [15-19].

Modern research methods of road pavement structures and the currently used computer programs are based on the theory of elasticity. This theory is most widely used in the model of road pavement structures where load transferred by the wheel tire to the road pavement causes stresses and strains in the pavement structure. In Lithuania, the structural layers of road pavement are selected according to the requirements of the currently valid normative documents, based on the research results of materials used in pavement structural layers and on engineering practice.

Today, Lithuania has a validated methodology, described in the Regulations for the Design of Standardized Road Pavement Structures KPT SDK 07, to select pavement structure based on only the design load A and there is no methodology to design pavement structure by determining thickness of the layers based on the quality indices of materials used.

It is especially topical to as accurately as possible predict the change in road pavement condition during its service life by taking into consideration thickness of pavement structural layers and the quality indices of materials used in the layers. Having studied and determined those quality indices there is a possibility to extend the service life of asphalt concrete pavements and to reduce the pavement repair and maintenance costs. It is topical to develop mathematical models which would enable to predict the change in pavement service indices based on the quality indices of pavement structural layers and of materials used in the layers.

\section{Properties and analyses of flexible road pavement structure courses and their materials}

Asphalt concrete pavements and their structures serve under individual (local) conditions which depend on the following factors: the properties of materials used in pavement and its structural layers, the properties of subgrade soil, thickness of the layers and their compaction degree, climatic conditions, vehicle loads and local conditions (groundwater level, local irrigation conditions), on the properties of asphalt concrete pavement and its structure (the pavement service indices: roughness $Y_{\mathrm{IRI}}$, rutting $H_{\mathrm{V}}$, degradation extent $D_{\mathrm{D}}$, pavement structural strength, etc.

Fig. 1 shows the model of interaction between the factors influencing the service conditions and properties of asphalt concrete pavement structure. The model studies the main factors having the most significant influence on roughness, rutting, degradation extent, structural strength and condition of asphalt concrete pavement. The factors given in Fig. 1 are not constant (determinate). A nature of their action is random, thus, their effect values vary randomly (stochastically) without exceeding certain limits. Some of these factors are of periodic nature: their values repeat periodically during the day (in the morning, in the evening and at night), also in the certain season of the year (in spring, summer, autumn and winter). The mentioned factors are air temperature and solar radiation forming a yearly balance of solar radiation. Another factors vary (within certain limits) completely randomly (the values of the majority of them vary according to the normal law): wind (its speed); amount of precipitation, vehicle loads; quality indices of asphalt concrete (AC) pavement and other pavement structural layers (thickness and compaction coefficient), composition of asphalt concrete of the pavement, physical, mechanical and other quality indices; grading of the materials of unbound pavement structural layers, and other quality indices; grading of subgrade soils, moisture and other indices of quality and strength.

The majority of the factors already discussed have a complex impact on the operational properties of asphalt concrete (AC) pavement (roughness $Y_{\mathrm{IRI}}$, rutting $H_{\mathrm{v}}$ ), road pavement structure (RPS) strength and condition. Very often the AC pavement and RPS are affected by several different factors at a time, thus determination of an effect of a single factor among several ones is complicated indeed. Schematic models of factors affecting the road pavement and other RPS courses are illustrated in the figures below (Fig. 2, a, b, c; Fig. 3, a, b; Fig. 4). Vertical plastic deformations of the RPS monolith courses move the unbound RPS courses found underneath. Displacement of particles of unbound mixtures takes place in the locations of RPS courses with cyclic plastic deformations of AC courses and the mixture skeleton is disintegrated this way with subsequent loss of initial bearing capacity of the RPS course. Decreased overall strength of RPS leads to worsening service indices of the road pavement (RP): formation of the damaged AC pavement locations and deterioration of the RP roughness. 


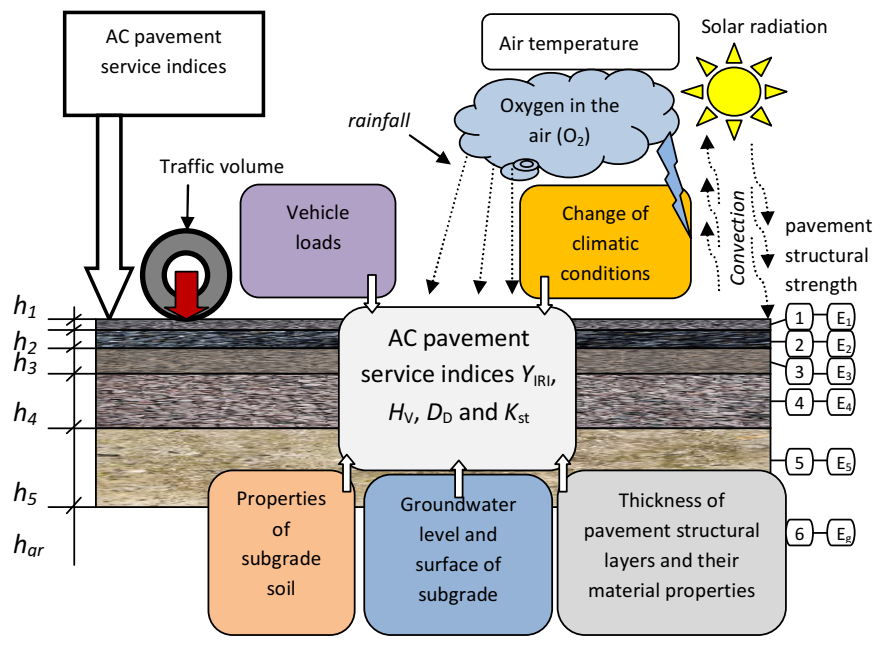

Fig. 1. The model of interaction between the factors influencing the asphalt concrete pavement roughness, rutting, degradation extent, structural strength and condition: 1-5 - pavement structural layers ( 1 - asphalt concrete wearing course, and 2 - asphalt concrete base courses; 3 - asphalt concrete road base; 4 - crushed stone or gravel sub-base; 5 -frost-blanket course from sand or other material); 6 - subgrade soil; $E_{1}-E_{5}$ and $h_{1}-h_{5}-$ moduli of elasticity and thicknesses of pavement structural layers, respectively; $E_{g r}$ and $h_{g r}$ - modulus of elasticity and equivalent thickness of the active zone of subgrade soil, respectively

a)

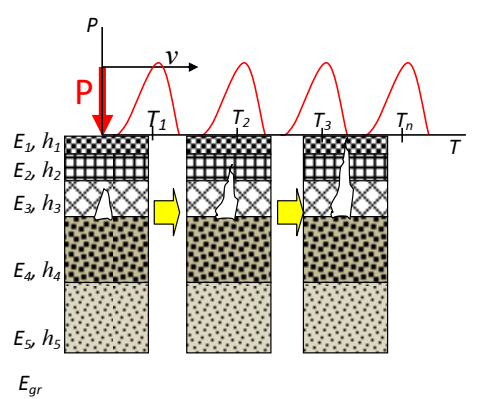

b)

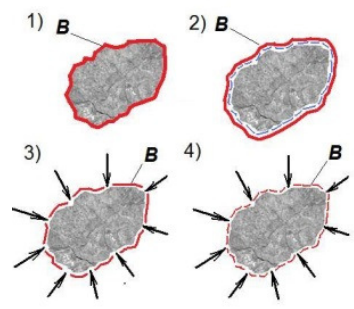

c)

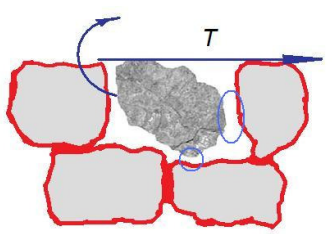

Fig. 2. Schematic model for the service life of asphalt concrete pavement structural layers and its influencing factors: $E_{1}-E_{5}$ ir $h_{1}-h_{5}-$ moduli of elasticity of the respective pavement structural layers and their thicknesses; $E_{\mathrm{gr}}$ ir $h_{\mathrm{gr}}$ - modulus of elasticity of the respective subgrade; $P$ - vehicle wheel load; $v$ - vehicle movement vector; $T_{1}-T_{\mathrm{n}}$ impact duration of the cyclic load caused by vehicle wheel; $B-$ membrane of bitumen binder; $T$ - vehicle movement direction

a)

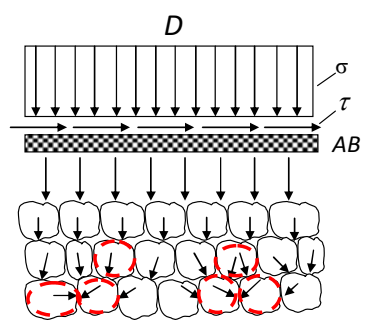

b)

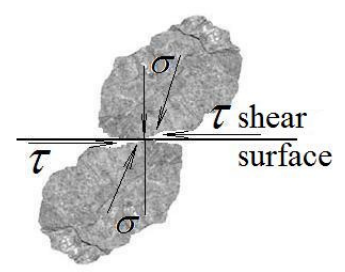

Fig. 3. Schematic model for the service life of unbound pavement structural layers and their influencing factors: $D$-the area of vehicle wheel action; AC - asphalt concrete pavement; $\sigma$-normal stresses; $\tau$ - tangential (shear) stresses; $P$ - vehicle wheel load

Unbound courses of the road pavement structure (RPS) are affected by normal stresses (distributed load) of vehicle wheels. The affecting loads are transferred to the RPS courses found beneath and the bound particles in the unbound RPS courses are displaced. They start moving among themselves. In the event of this phenomenon in the unbound RPS course, shear forces emerge among the moving particles. Friction among weak particles results in polishing of sharp grain edges, which further leads to weakening of contact among them (shear forces). Loose particles start moving and disintegrate the frame of the course material and the unbound RPS course loses its strength. 

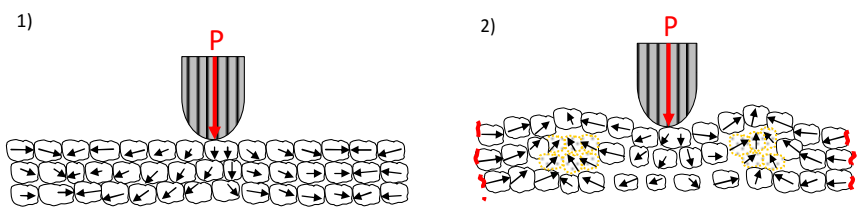

Fig. 4. The model of rutting in flexible road pavement: 1) beginning of the process;

2 ) the long-time process after several (3-5 or more) years, P - vehicle wheel load

Compression of the bound AC particles in monolith flexible RPS courses takes place in the wheel impact zone when traffic is on. The compressed particles transfer loads to the adjoining particles which push the farther particles away from themselves. With the displacement of particles from their original locations the AC skeleton loses its homogeneity. In the places of vehicle wheel impact the particles undergo thinning and they are displaced to different sides while the particles available on the sides come closer to each other. Air voids are formed in the places of the thinned particles and degradation starts in the places of particles compaction. While compressing each other the weak particles crumble and turn fine. The AC pavement is no longer strong and its fatigue is observed. In the event of the said movement of particles rut formation in the AC pavement is witnessed.

For the research purposes the main road Kaunas-Marijampolè-Suvalkai (Via Baltica) was selected, the second road by the highest indices of traffic volume, reconstruction of the study sections of which was implemented in 2005.

Having divided the road into sections with the same structural and geometrical pavement characteristics two experimental sections were selected. The length of the first experimental section is $6.8 \mathrm{~km}$, of the second $-4.5 \mathrm{~km}$. The experimental road sections were selected in a way that their equivalent single axle load (ESAL) was different (Fig. 5), while, the road pavement structures and the materials used were as similar as possible.

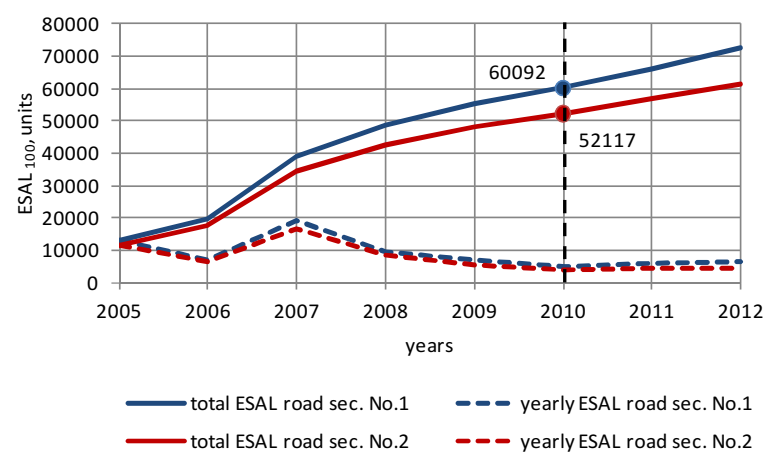

Fig. 5. Change in the traffic volume of the experimental road sections, 2005-2012

In 2007, measurements of pavement roughness $Y_{I R I}$, rut depth $H_{\mathrm{v}}$ and degradation extent $D_{\mathrm{D}}$ were carried out on the study road. The in-depth investigations of road pavement condition were carried out using the mobile road surface tester. The samples taken from the road were tested in the laboratory.

Experimental research was carried out in the laboratory and in-situ. Research methodology consisted of two major parts: testing the quality indices of materials used in road pavement structures in the laboratory and measuring pavement service indices after road reconstruction (Fig. 6).

Sampling of asphalt mixtures was initiated from the material placed immediately at the asphalt paver augers. Two regular samples for AC testing of approximately $7 \mathrm{~kg}$ in weight were taken with a sampling shovel from both paver sides observing LST EN 12697-27 standard requirements. A sample delivered to a laboratory was divided into portions (quartered) to perform the following analyses:

- Particle size distribution of mineral material;

- Bituminous binder $B$ content (via differential method), mass \%;

- The bulk density of asphalt mixture;

- The maximum density of asphalt mixture;

- Air voids index of the asphalt mixture.

Extraction of asphalt mixture relying on a special laboratory equipment (Fig. 7, a) was made to determine the bituminous binder $B$ content via differential method according to LST EN 12697-1. The binder $B$ content (by means of extraction) was found by washing out the binder from the asphalt mixture with a solvent. The binder content as per differential method was determined by application of the below Eqn.:

$$
S=\frac{100 \times\left[M-\left(M_{1}+M_{W}\right)\right]}{M-M_{W}}
$$


where: $S$ - soluble binder content , \%; $M$ - mass of non-dried tested portion, $\mathrm{g} ; M_{1}-$ mass of regenerated mineral material, $\mathrm{g} ; M_{\mathrm{W}}-$ water mass of non-dried tested portion, $\mathrm{g}$.

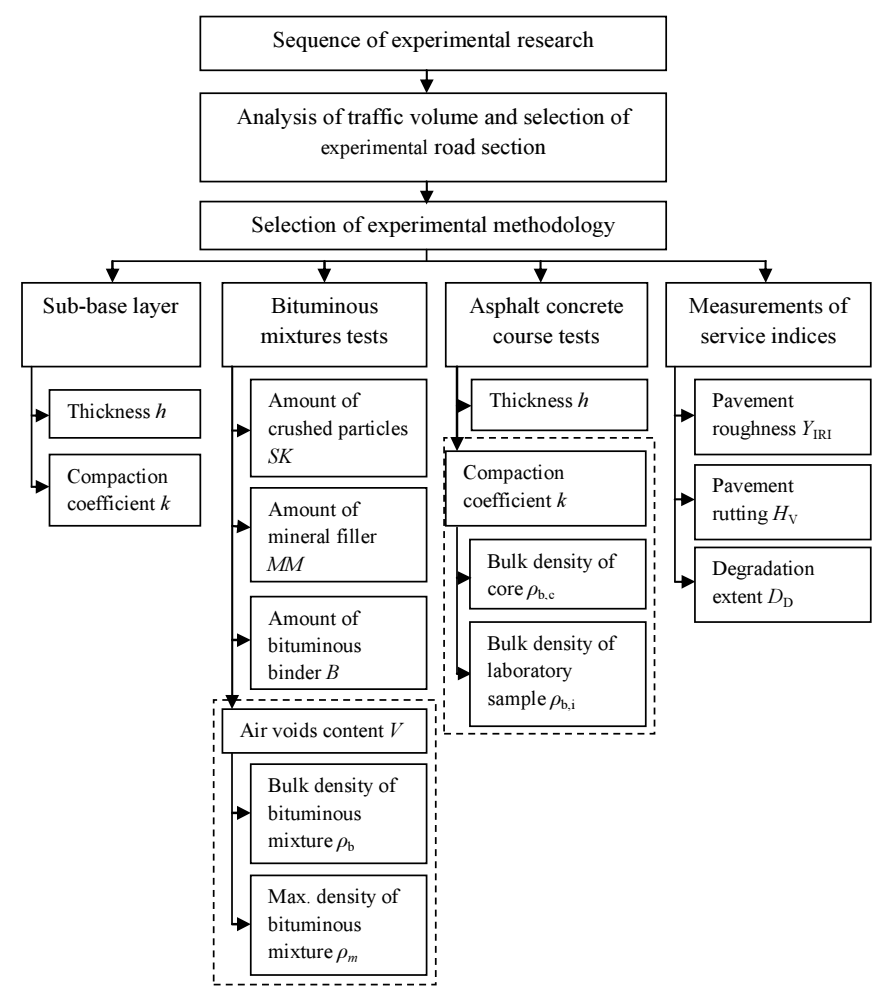

Fig. 6. The scheme of the sequence of experimental research

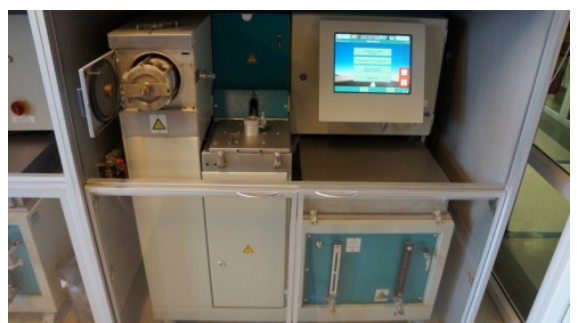

a)

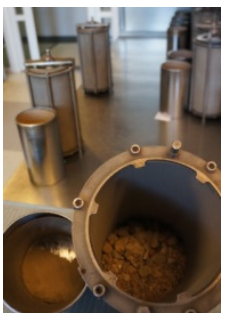

b)

Fig. 7. Laboratory equipment for the determination of bitumen binder content and grading of asphalt concrete mixture

Determination of particle size distribution of mineral material of asphalt mixtures by means of testing is made via sieving and weighing. Analysis of mineral material is done upon bituminous binder extraction. The mineral material particles left in a centrifuge and mineral powder (Fig. 7b) are sieved and washed in respective mesh size (mm) sieves. A part of the mineral material mass, which has been trapped on $2 \mathrm{~mm}$ mesh size sieves and having passed through $0.09 \mathrm{~mm}$ mesh size sieves was selected for this particular analysis.

A sample delivered to a laboratory for determination of the porosity index of the asphalt mixture according to LST EN 12697-30 was divided into 2 portions (quartered). One portion of the sample (from $1050 \mathrm{~g}$ to $1400 \mathrm{~g}$ in weight) was heated to $140-150^{\circ} \mathrm{C}$ temperature, poured to the heated $\left(<+150^{\circ} \mathrm{C}\right)$ mould and compacted with a special Marshall's compactor Fig. $(8, a)$. This way the needed height sample $(60.5-66.5 \mathrm{~mm})$ was compacted. 


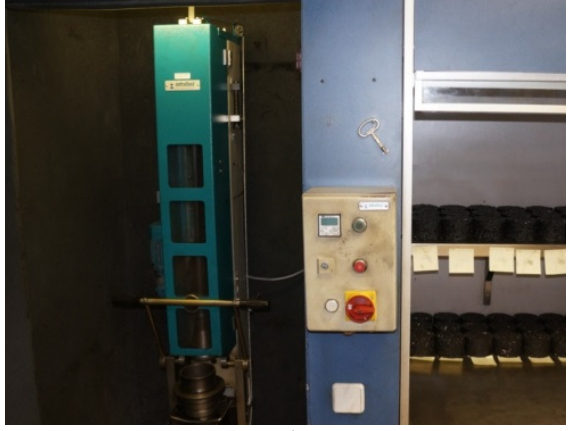

a)

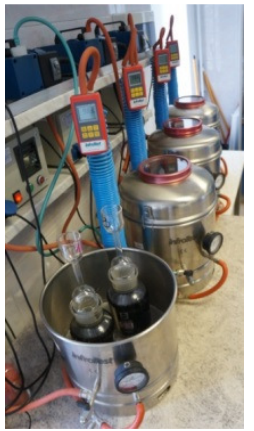

b)

Fig. 8. Laboratory equipment for forming asphalt concrete samples and defining the expected and maximum density

The bulk density of AC mixture $\rho_{\mathrm{b}}$ according to LST EN 12697-6 was determined after the sample measuring for its height and diameter, and after the sample weighing. The second portion of the quartered AC sample was crushed by hand taking care of the integrity of particles contained in the mixture. The ready sample was poured to pycnometer filled with water and inserted into a vacuum vessel (Fig. 8, b). Afterwards the sample weighing took place (after vacuuming) and the maximum density of asphalt mixture $\rho$ m based on LST EN 12697-5 was determined. Air voids content in the compacted AC samples was determined following LST EN 12697-8, Eqn. (2):

$$
V_{m}=\frac{\rho_{m}-\rho_{b}}{\rho_{m}} \times 100 \%
$$

where: $V_{m}$ Air voids content, $\% ; \rho_{m}$ - the maximum density of mixture, $\mathrm{Mg} / \mathrm{m}^{3} ; \rho_{b}-$ the apparent density of mixture, $\mathrm{Mg} / \mathrm{m}^{3}$.

For quality control of the constructed road AC pavement, sampling (core drilling) locations on the pavement were selected and a number of samples was set as required for subsequent analyses of asphalt concrete. The locations for drilling of asphalt concrete cores were selected on the random number theory basis.

After the samples (cores) have been drilled, the core heights were measured with callipers and an actual thickness of an individual AC pavement course based on LST EN 12697-29 was determined. A degree of AC mixture compaction $k$ was calculated with the known volumetric density $\rho_{b, c}$ of the AC pavement sample (core) and volumetric density $\rho_{b, i}$ of the AC sample of the drilled cores with the sample produced according to LST EN 12697-30, Eqn. (3):

$$
k=\frac{\rho_{b, c}}{\rho_{b, i}} \cdot 100 \%
$$

where: $\rho_{b, c}$ is the bulk density of AC samples (cores) $\mathrm{t}, \mathrm{Mg} / \mathrm{m}^{3} ; \rho_{b, i}-$ the bulk density of, $\mathrm{Mg} / \mathrm{m}^{3}$.

Measurements of road pavement roughness according to $Y_{\mathrm{IRI}}$, rut depth index $H \mathrm{v}$ and degradation degree $D_{\mathrm{D}}$ were determined and assessed on A5 highway in 2007. They were repeatedly performed in the same highway sections in 2010. Overall analyses of road pavement condition relied on RST-28, a mobile Mobile road surface tester. Higher rate results, i.e. those of the right rut depth, were analysed in the calculations.

Table 1 presents a number of analyses performed to measure the service indices of the road pavement for the first and second experimental road sections.

The statistical analysis was based on the testing results of asphalt concrete samples (mixtures and cores) taken from the same road sites (20 in the first section and 18 in the second section) and on the measurement results of pavement service indices.

Table 1. The total amount of experimental research

\begin{tabular}{lll}
\hline Index & \multicolumn{2}{l}{ Experimental sections } \\
\cline { 2 - 3 } & \multicolumn{1}{l}{ The first } & \multicolumn{1}{c}{ The second } \\
\cline { 2 - 3 } & \multicolumn{2}{l}{ Number of tests (measurements), pcs. } \\
\hline The road pavement roughness $Y_{\mathrm{IRI}}$ & 643 & 226 \\
\hline The road pavement rutting $H_{\mathrm{V}}$ & 643 & 226 \\
\hline The road pavement degradation extend $D_{\mathrm{D}}$ & 643 & 226 \\
\hline Sampling location, Pk & 21 & 18 \\
\hline Bituminous binder content $B_{\mathrm{S}}$, mass $\%$ & 21 & 18 \\
\hline Bituminous binder content $B_{\mathrm{AS}}$, mass $\%$ & 21 & 18 \\
\hline Bituminous binder content $B_{\mathrm{PS}}$, mass $\%$ & 21 & 18 \\
\hline Particle size distribution of $\mathrm{AC}$ mixture $\left(S K_{\mathrm{S}} ; M M_{\mathrm{S}}\right.$ content, mass \%) & 21 & 18 \\
\hline
\end{tabular}


M. Bulevičius et al. / The $9^{\text {th }}$ Conference Environmental Engineering. Selected Papers, Article number: enviro. 2014.148

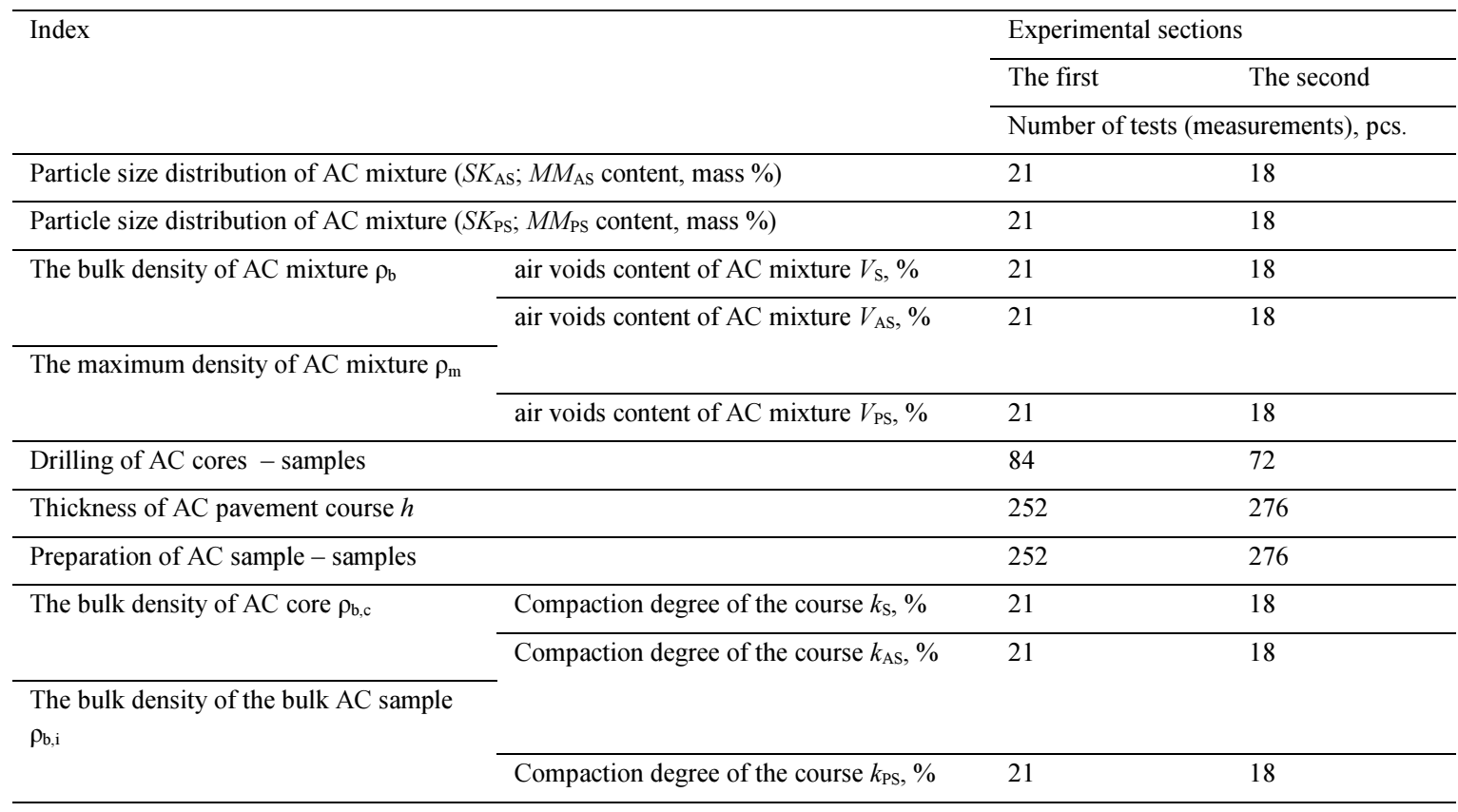

\section{Assessment of structural courses, property analysis and their materials}

The test results have been processed relying on Maple 10 Academic edition software for determination of their distribution in terms of correlation coefficient $R$, determination coefficient $R^{2}$ and regression Equations. Upon grouping of the analyzed indices (STATISTIKA 7 software), the following has been derived: mathematical models for the dependence of the analyzed indices on the input parameters (variables); correlation matrix; calculated Equation of linear regression. For the obtained research results the inter-correlations were calculated and mathematical models were developed (regression Equations of linear dependence (4), (5), (6), (7) for the prediction of road pavement condition (service indices $Y_{\text {IRI }}$ and $H_{\mathrm{V}}$ ).

Mathematical models for the prediction of service indices of asphalt concrete pavement were developed as follows: (4), (5) for the first experimental road section with the total $A A D T \leq 30000$ veh./day and (6), (7) for the second experimental road section with the total $A A D T \leq 10000$ veh./day:

$$
\begin{aligned}
& Y_{\mathrm{IRI}}=0.114 \cdot V_{\mathrm{S}}+0.203 \cdot B_{\mathrm{S}}+0.446 \cdot S K_{\mathrm{S}}+0.014 \cdot M M_{\mathrm{S}}+0.267 \cdot B / M M_{\mathrm{S}}-0.075 \cdot V_{\mathrm{AS}}- \\
& 0.287 \cdot B_{\mathrm{AS}}-0.151 \cdot S K_{\mathrm{AS}}+0.023 \cdot M M_{\mathrm{AS}}-0.321 \cdot B / M M_{\mathrm{AS}}-0.318 \cdot V_{\mathrm{PS}}-0.136 \cdot B_{\mathrm{PS}}+ \\
& 0.085 \cdot S K_{\mathrm{PS}}-0.321 \cdot M M_{\mathrm{PS}}+0.068 \cdot B / M M_{\mathrm{PS}}+0.351 \cdot k_{\mathrm{S}}-0.147 \cdot k_{\mathrm{AS}}+0.093 \cdot k_{\mathrm{PS}}- \\
& 0.289 \cdot h_{\mathrm{S}}+0.01 \cdot h_{\mathrm{AS}}+0,071 \cdot h_{\mathrm{PS}}-0.066 \cdot h_{\mathrm{Sk}}+0.214 \cdot h_{\mathrm{S}} \mathrm{AS}, \text { where } R^{2}=0.69,
\end{aligned}
$$$$
H_{\mathrm{V}}=0.118 \cdot V_{\mathrm{S}}-0.078 \cdot B_{\mathrm{S}}+0.467 \cdot S K_{\mathrm{S}}+0.023 \cdot M M_{\mathrm{S}}-0.069 \cdot B / M M_{\mathrm{S}}+0.072 \cdot V_{\mathrm{AS}}+
$$$$
0.117 \cdot B_{\mathrm{AS}}+0.33 \cdot S K_{\mathrm{AS}}+0.023 \cdot M M_{\mathrm{AS}}+0.104 \cdot B / M M_{\mathrm{AS}}+0.078 \cdot V_{\mathrm{PS}}+0.212 \cdot B_{\mathrm{PS}}+
$$$$
0.055 \cdot S K_{\mathrm{PS}}-0.119 \cdot M M_{\mathrm{PS}}+0.082 \cdot B / M M_{\mathrm{PS}}+0.325 \cdot k_{\mathrm{S}}+0.042 \cdot k_{\mathrm{AS}}+0.014 \cdot k_{\mathrm{PS}}+
$$$$
0.299 \cdot h_{\mathrm{S}}+0.017 \cdot h_{\mathrm{AS}}-0.184 \cdot h_{\mathrm{PS}}+0.104 \cdot h_{\mathrm{Sk}}-0.522 \cdot h_{\mathrm{S} \mathrm{AS}} \text {, where } R^{2}=0.83 \text {, }
$$$$
Y_{\mathrm{IRI}}=0.134 \cdot V_{\mathrm{S}}-0.142 \cdot B_{\mathrm{S}}-0.05 \cdot S K_{\mathrm{S}}-0.124 \cdot M M_{\mathrm{S}}+0.044 \cdot B / M M_{\mathrm{S}}+0.117 \cdot V_{\mathrm{AS}}
$$$$
0.033 \cdot B_{\mathrm{AS}}-0.257 \cdot S K_{\mathrm{AS}}+0.027 \cdot M M_{\mathrm{AS}}-0.056 \cdot B / M M_{\mathrm{AS}}+0.303 \cdot V_{\mathrm{PS}}+0.09 \cdot B_{\mathrm{PS}}-
$$$$
0.179 \cdot S K_{\mathrm{PS}}+0.212 \cdot M M_{\mathrm{PS}}-0.223 \cdot B / M M_{\mathrm{PS}}-0.126 \cdot k_{\mathrm{S}}-0.161 \cdot k_{\mathrm{AS}}-0.162 \cdot k_{\mathrm{PS}}+
$$$$
0.175 \cdot h_{\mathrm{S}}+0.217 \cdot h_{\mathrm{AS}}+0.115 \cdot h_{\mathrm{PS}}+0.533 \cdot h_{\mathrm{Sk}}+0.409 \cdot h_{\mathrm{S}} \mathrm{AS} \text {, where } R^{2}=0.69 \text {, }
$$

$$
\begin{aligned}
& H_{\mathrm{V}}=0.458 \cdot V_{\mathrm{S}}+0.166 \cdot B_{\mathrm{S}}+0.065 \cdot S K_{\mathrm{S}}+0.012 \cdot M M_{\mathrm{S}}+0.082 \cdot B / M M_{\mathrm{S}}-0.144 \cdot V_{\mathrm{AS}}- \\
& 0.124 \cdot B_{\mathrm{AS}}+0.308 \cdot S K_{\mathrm{AS}}+0.056 \cdot M M_{\mathrm{AS}}-0.256 \cdot B / M M_{\mathrm{AS}}+0.277 \cdot V_{\mathrm{PS}}+0.326 \cdot B_{\mathrm{PS}}- \\
& 0.289 \cdot S K_{\mathrm{PS}}+0.37 \cdot M M_{\mathrm{PS}}-0.154 \cdot B / M M_{\mathrm{PS}}-0.24 \cdot k_{\mathrm{S}}+0.022 \cdot k_{\mathrm{A}}-0.011 \cdot k_{\mathrm{PS}}-0.189 \cdot h_{\mathrm{S}}+ \\
& 0.24 \cdot h_{\mathrm{AS}}-0.123 \cdot h_{\mathrm{PS}}+0.07 \cdot h_{\mathrm{Sk}}-0.08 \cdot h_{\mathrm{SS}}, \text { where } R^{2}=0.85,
\end{aligned}
$$

where $Y_{\mathrm{IRI}}-$ International Roughness Index, $\mathrm{m} / \mathrm{km}, H_{\mathrm{V}}-$ rut depth of the road pavement, $\mathrm{mm}, V_{\mathrm{S}}, V_{\mathrm{AS}}, V_{\mathrm{PS}}-$ the index of air voids content in the mixture of respective asphalt concrete layer $(\mathrm{S}$ - asphalt concrete wearing course, AS - asphalt concrete base course, PS - asphalt concrete road base), $B_{\mathrm{S}}, B_{\mathrm{AS}}, B_{\mathrm{PS}}$ - binder content in the mixture of respective asphalt concrete layer, $S K_{\mathrm{S}}, S K_{\mathrm{AS}}, S K_{\mathrm{PS}}$ - the amount of retained aggregate on the $2 \mathrm{~mm}$ diameter sieve of respective asphalt concrete layer, $M M_{\mathrm{S}}, M M_{\mathrm{AS}}, M M_{\mathrm{PS}}$ - the amount of aggregate passing through the $0.09 \mathrm{~mm}$ diameter sieve of respective asphalt concrete layer, $B / M M_{\mathrm{S}}, B / M M_{\mathrm{AS}}, B / M M_{\mathrm{PS}}$ - the ratio of binder and mineral filler in asphalt concrete mixture of respective asphalt 
concrete layer, $k_{\mathrm{S}}, k_{\mathrm{AS}}, k_{\mathrm{PS}}-$ compaction index of respective asphalt concrete layer, $h_{\mathrm{S}}, h_{\mathrm{AS}}, h_{\mathrm{PS}}, h_{\mathrm{Sk}}, h_{\mathrm{S} \mathrm{AS}}-$ thickness of respective pavement structural layer.

The variables (indices) of the derived equation to forecast the pavement condition have been analysed using the analytic distribution software EasyFit 5.5 professional and the closest distribution has been determined for each input of variables. 1000 random values have been generated via Monte Carlo method following the functions of the determined distributions for individual variables (indices).

Multiplatform MathWorks software MATLAB has been employed for probability analysis of uncertainty of variable (index) modelling data. Sensitivity analysis for each derived linear regression equation has been conducted by applying the Monte Carlo method and selecting standardized regression coefficients (SRC) for sensitivity indices.

The developed formula enabled solving of the equation uncertainty task and calculation of sensitivity of an individual index of equation. The result uncertainty and sensitivity analysis has been based on the probability method. The applied parameters included the incidental/random rates and the values assumed by them were described by probabilistic distribution laws.

The obtained results in Fig. 9 point to the fact that the major impact on the uncertainty of index $Y_{I R I}$ of the first experimental section of road is made by the uncertainty of parameters $S K_{\mathrm{S}}$ (the amount of retained aggregate on $2 \mathrm{~mm}$ diameter mesh size sieve) and $k_{\mathrm{S}}$ (thickness of the top course of asphalt concrete pavement). Uncertainty of indices $B / M M_{\mathrm{AS}}$ (ratio between the bottom course of asphalt concrete bituminous binder and mineral powder), $V_{\mathrm{PS}}$ (porosity index of the base course asphalt concrete) and $M M_{\mathrm{PS}}$ (content of the base course of asphalt concrete mineral material passed through $0.09 \mathrm{~mm}$ diameter mesh size sieve) is less significant.

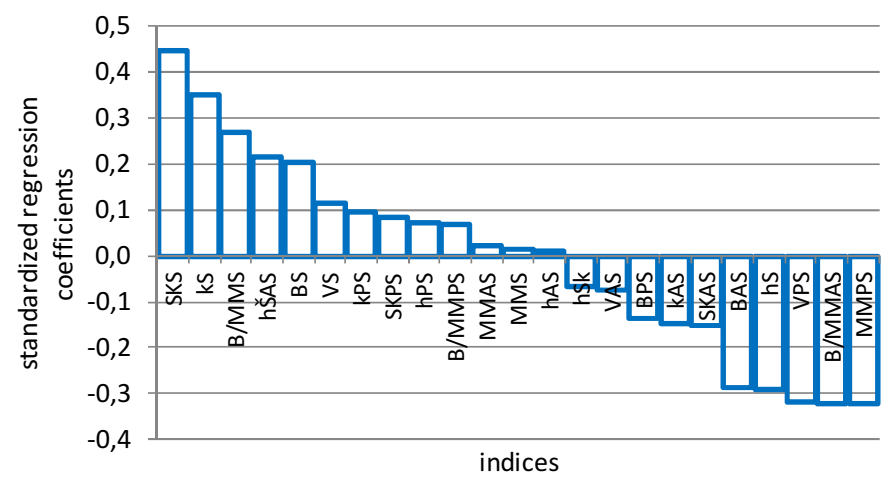

Fig. 9. Results of probabilistic sensitivity analysis of roughness index modelling for the first experimental road section

It is revealed by positive SRC values of sensitivity indices that the increase of the said parameters also leads to the increase of $Y_{I R I}$ index values. Reverse relationship is observed between the values of the analyzed pavement roughness index $Y_{I R I}$ and significant indices $B_{\mathrm{AS}}, B / M M_{\mathrm{AS}}, V_{\mathrm{PS}}, M M_{\mathrm{PS}}, h_{\mathrm{S}}$ (content of bituminous binder of the base course asphalt concrete and its relation with mineral powder, air voids content of the base course asphalt concrete and mineral powder content and the wearing course thickness of asphalt concrete pavement respectively) - the increase of values of the abovementioned indices leads to the reduction of the value gained by $Y_{I R I}$ index. Following the derived results and aiming at the reduction of uncertainty of $Y_{I R I}$, it would be expedient if further analyses are focused primarily on a more accurate assessment of uncertainty of the distinguished parameters. This can be achieved by increasing a number of control tests, checking of crushed stone content in asphalt concrete during installation of the top course of AC pavement and improving of construction work quality of the $\mathrm{AC}$ wearing course. Uncertainty of the remaining indices has no significant impact on the uncertainty of $Y_{I R I}$ index modelling results.

The major impact on the uncertainty of the rut depth index $H_{\mathrm{v}}$ modelling results, as illustrated in Fig. 10, for the first experimental section is made by the uncertainty of index $S K_{S}$ (content of the remainder of the wearing course of asphalt concrete mineral material on $2 \mathrm{~mm}$ diameter mesh size sieve), like in the event of index $Y_{I R I}$, and index $h_{\mathrm{S} A S}$ (thickness of frost resistant course) ( $\mathrm{SRC}=0.47$ and $(-0.52)$ respectively) and slightly less significant uncertainty of indices $S K_{\mathrm{AS}}, B_{\mathrm{PS}}, k \mathrm{~s}$ and $h_{\mathrm{S}}$ (the amount of retained aggregate of the road base asphalt concrete course on $2 \mathrm{~mm}$ diameter mesh size sieve, the content of bituminous binder of the asphalt concrete base course and the top course thickness of AC pavement and compaction coefficient respectively) (SRC from 0.2 to 0.3 ).

The strongest reverse relationship of the rut depth index $H_{\mathrm{v}}$ and the thickness of frost retarding course $h$ šss is observed. Following the derived results and aiming at the uncertainty reduction of $H_{\mathrm{v}}$, it would be expedient if further analyses are focused primarily on a more accurate specification of mineral material for the wearing and base courses of AC pavement, thickness and compaction control of the top AC pavement course and a more stringent control of the thickness of frost resistant course. Uncertainty of the remaining indices has no significant impact on the uncertainty of $H_{\mathrm{v}}$ index modelling results. 


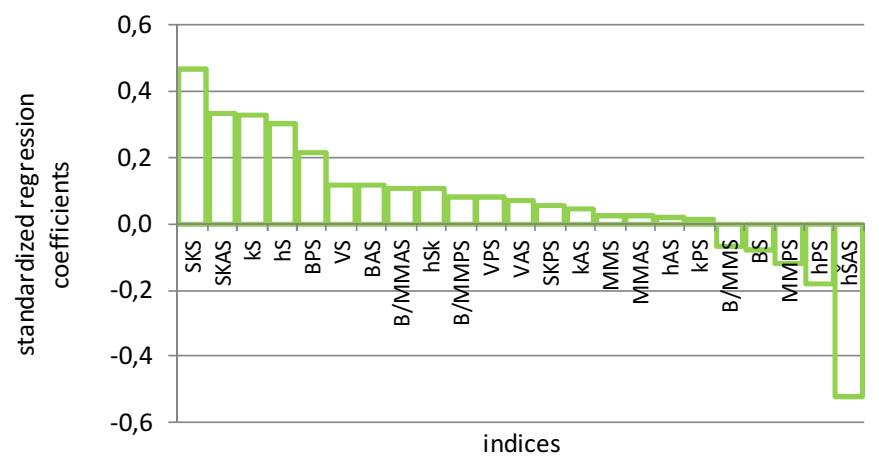

Fig. 10. Results of probabilistic sensitivity analysis of rutting index modelling for the first experimental road section

Fig. 11 includes the equation sensitivity indices computed for the second experimental road section $Y_{\text {IRI. The major }}$ impact on the uncertainty of index $Y_{\mathrm{IRI}}$ for the second experimental road section is made by the uncertainty of indices $h_{\mathrm{Sk}}$, $h_{\text {ŠAS }}$ (thicknesses of the crushed stone road base and frost resistant course respectively) with less significant uncertainty of indices $V_{\mathrm{PS}}, M M_{\mathrm{PS}}, S K_{\mathrm{AS}}, B / M M_{\mathrm{PS}}, h_{\mathrm{AS}}$ (air voids content in the AC base course, the ratio of bituminous binder and mineral powder and the content of mineral powder, as well as the thickness of asphalt concrete course and the content of crushed stone in AC).

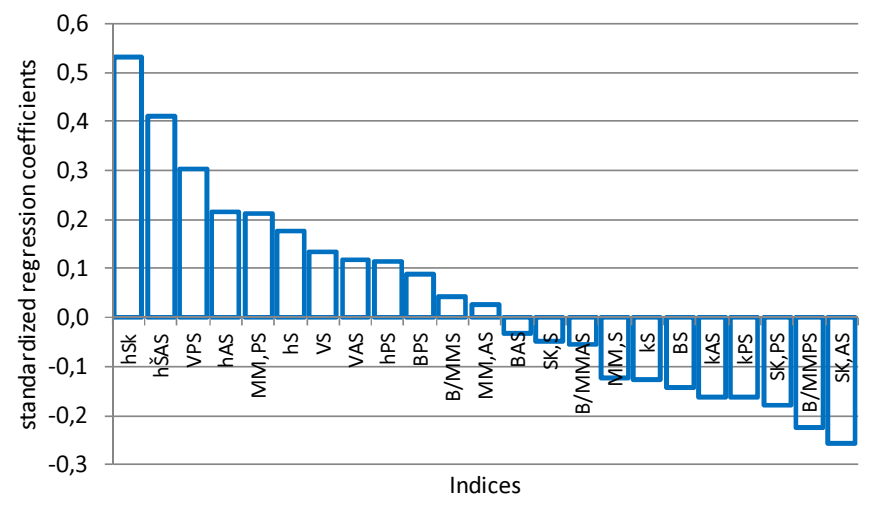

Fig. 11. Results of probabilistic sensitivity analysis of roughness index modelling for the second experimental road section

It is revealed by positive SRC values of sensitivity indices that the increase of the said parameters also leads to the increase of $Y_{\text {IRI }}$ index values. Reverse relationship is observed between the values of the analyzed index $Y_{I R I}$ and significant indices $\left(M M_{\mathrm{PS}}, S K_{\mathrm{AS}}, B / M M_{\mathrm{PS}}\right)$ - the increase in the sensitivity values leads to the reduction of the value gained by $Y_{\mathrm{IRI}}$ index. Following the derived results and aiming at the reduction of uncertainty of $Y_{\text {IRI, }}$ it would be expedient if further analyses are focused primarily on the road base construction control analyses, i.e. a more accurate assessment of the thickness uncertainty of courses needs to be conducted. Uncertainty of other parameters has no significant impact on the uncertainty of $Y_{\mathrm{IRI}}$ index modelling results.

The major impact on the uncertainty of the rut depth index $H_{\mathrm{v}}$ modelling results, as illustrated in Fig. 12, for the second experimental section is made by the uncertainty of air voids content in the AC wearing course and index $V_{\mathrm{S}}(\mathrm{SRC}=0.46)$, with less significant uncertainty of indices $S K_{\mathrm{AS}}, B / M M_{\mathrm{AS}}, V_{\mathrm{PS}}, B_{\mathrm{PS}}, S K_{\mathrm{PS}}, M M_{\mathrm{PS}}, k_{\mathrm{S}}, h_{\mathrm{AS}}$ (the content of crushed stone in the road base course of $A C$ pavement, the ratio of bituminous binder and mineral powder, air voids content in the base course of $\mathrm{AC}$ and the content of bituminous binder, as well as the content of crushed stone and mineral powder; AC wearing course compaction index and thickness of AC road base course).

The obtained results in Fig. 12 point to the fact that the reverse relationship of index $H_{\mathrm{v}}$ is due to the content of bituminous binder in the base course of $\mathrm{AC}$, particle size distribution of crushed stone contained in the base course and the content of bituminous binder $\left(B / M M_{\mathrm{AS}}, S K_{\mathrm{PS}}, B_{\mathrm{PS}}\right.$ accordingly).

Following the derived results and aiming at the reduction of uncertainty of index $H_{\mathrm{v}}$, it would be expedient if further analyses are focused primarily on a more accurate assessment of uncertainty of the top AC pavement course air voids content $V_{\mathrm{S}}$ and specification of $S K_{\mathrm{AS}}, B / M M_{\mathrm{AS}}, V_{\mathrm{PS}}, B_{\mathrm{PS}}, S K_{\mathrm{PS}}, M M_{\mathrm{PS}}, k_{\mathrm{S}}, h_{\mathrm{AS}}$ indices. Uncertainty of the remaining indices has no major impact on the uncertainty of $H_{\mathrm{v}}$ index modelling result.

Having calculated the uncertainty of mathematical models, the limits were determined where the values of pavement quality indices vary. When modelling rational road pavement structure the values of predicted road pavement indices were determined at a reliability degree $\alpha=0.05$. 


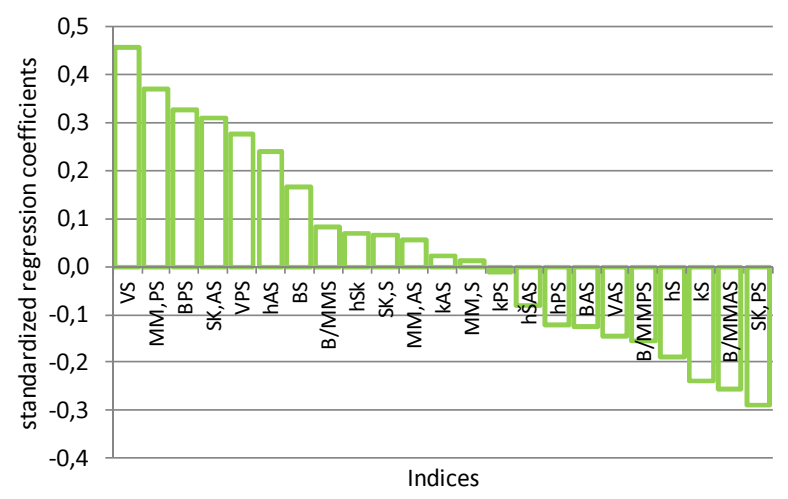

Fig. 12. Results of probabilistic sensitivity analysis of rutting index modelling for the second experimental road section

Uncertainty analysis for the results of developed Eqns (4)-(7) was carried out in a probability technique with the help of Monte Carlo method. For the analysis, in a random order 1000 index values were selected from their probability distribution and modelling of the generated values was carried out.

Based on the determined cumulative functions (presented in the dissertation) it could be stated that according to the calculated mathematical models for the prediction of road pavement service indices, at a 0.95 reliability the index $Y_{\text {IRI }}$ will get the value $Y_{\text {IRI }} \leq 1.6 \mathrm{~m} / \mathrm{km}$, and the index $H \mathrm{v} \leq 7 \mathrm{~mm}$ in the first experimental road section. Correspondingly, it could be stated that at a 0.95 reliability the index $Y_{\text {IRI }}$ will get the value $Y_{\text {IRI }} \leq 1.6 \mathrm{~m} / \mathrm{km}$, and the index $H \mathrm{v} \leq 4 \mathrm{~mm}$ in the second experimental road section.

\section{Conclusions}

1. When predicting the values of service indices pavement roughness and rut depth of asphalt concrete pavements of the main roads (for a five-year period) the use of mathematical models (regression dependences) is suggested to predict the mentioned indices. The following coefficients of determination were obtained -0.69 for the determination of road pavement roughness and 0.83 for the determination of pavement rutting, where annual average daily traffic is not greater than $30000 \mathrm{veh} . /$ day, 0.69 for the determination of road pavement roughness and 0.85 for the determination of pavement rutting where annual average daily traffic is not greater than $10000 \mathrm{veh} . /$ day.

2. Sensitivity analysis of the linear regression equations for the prediction of service indices road pavement roughness and pavement rutting of asphalt concrete pavements showed that:

- uncertainty of the pavement roughness index for the first experimental road section can be most efficiently reduced by revising the uncertainty value of retained aggregate of the asphalt concrete wearing course on the 2 mm diameter sieve and thickness of the wearing course of asphalt concrete pavement, and uncertainty of the pavement rut depth index - by revising the uncertainty value of parameters retained aggregate of the asphalt concrete wearing course on the $2 \mathrm{~mm}$ diameter sieve and thickness of the frost-blanket course;

- uncertainty of the pavement roughness index for the second experimental road section can be most efficiently reduced by revising the uncertainty value of parameters thickness of the aggregate base and the frost-blanket course, respectively, and uncertainty of the pavement rut depth index - by reducing uncertainty of the voids content index of the wearing course of asphalt concrete pavement.

3. Based on the developed mathematical models for the prediction of service indices of asphalt concrete pavement in case where annual average daily traffic is not greater than 10000 veh./day the pavement roughness index will get the value not greater than $1.6 \mathrm{~m} / \mathrm{km}$ and the rut depth index - the value not greater than $4 \mathrm{~mm}$ at a $95 \%$ reliability, in case where annual average daily traffic is not greater than $30000 \mathrm{veh} . /$ day the pavement roughness index will get the value not greater than $1.6 \mathrm{~m} / \mathrm{km}$ and the pavement rut depth index - the value not greater $7 \mathrm{~mm}$, at a $95 \%$ reliability.

\section{References}

[1] Čygas, D.; Laurinavičius, A.; Vaitkus, A.; Perveneckas, Z.; Motiejūnas, A.2008. Research of asphalt pavement structures on Lithuanian roads (I), The Baltic Journal of Road and Bridge Engineering 3(2): 77-83. http://dx.doi.org/10.3846/1822-427X.2008.3.77-83

[2] Laurinavicius, A.; Vaitkus, A.; Bertuliene, L.; Tuminiene, F.; Ziliute, L. 2009. Research of experimental road pavement structures in Lithuania, Proceedings of II International Conference Environmentally Friendly Roads-ENVIROAD 2009, editor D. Sybilski, Poland, 6 p.

[3] Motiejūnas, A.; Paliukaitè, M.; Vaitkus, A.; Čygas, D.; Laurinavičius, A. 2010. Research of Dependence of Asphalt Pavement Stiffness upon the Temperature of Pavement Layers, The Baltic Journal of Road and Bridge Engineering 5(1): 50-54. http://dx.doi.org/10.3846/bjrbe.2010.07

[4] Klashinsky, R.; Hanson, R.; McGibney, S. 2010. Strategic Commercial Vehicle Enforcement to Reduce GHG Emissions and Infrastructure Damage. International Road Dynamics Inc.

[5] Karkowski, M.; Rafalski, L. 2013. The problem of overloaded vehicles in Poland, in The XXVIII International Baltic Road Conference, 8 p. 
[6] Sokolov, J.; Sivilevičius, H. 2011. Sunkiụjų automobilių sąveikos su kelio danga ir jų įtakos konstrukcijos sluoksniams analizė, Mokslas - Lietuvos ateitis 3(2): 103-109.

[7] Marzouk, M.; Awad, E.; Moheeb, El-Said. 2012. An Integrated Tool for Optimizing Rehabilitation Programs of Highways Pavement, The Baltic Journal of Road and Bridge Engineering (7)4: 297-304. http://dx.doi.org/10.3846/bjrbe.2012.39

[8] Pradhan, N. P.; Hennig, T.; Wilson, D. J. 2001. Development of pavement deterioration modeling in New Zealand. A Rewiew of Achievements. HTC Infrastructure Management Ltd. $56 \mathrm{p}$.

[9] Ioannides, A. M., Tallapragada, P. K. 2013. An overview and a case study of pavement performance prediction, International Journal of Pavement Engineering 14(7): 629-644. http://dx.doi.org/10.1080/10298436.2012.715644

[10] Thodesen, C. C.; Lerfald, B. O.; Hoff, I. 2012. Review of asphalt pavement evaluation methods and current applications in Norway, The Baltic Journal of Road and Bridge Engineering 7(4): 246-252. http://dx.doi.org/10.3846/bjrbe.2012.33

[11] Žilionienè, D.; De L., M.; Dellacqua, G.2013. Evaluation of climatic factors based on the mechanistic -empiric al pavement de sign guide, The Baltic Journal of Road and Bridge Engineering 8(3): 158-165. ISSN 1822-427X.

[12] Wu, Z.; Yang, X.; Zhang, Z. 2013. Evaluation of MEPDG flexible pavement design using pavement management system data: Louisiana experience, International Journal of Pavement Engineering 14(7): 674-685. http://dx.doi.org/10.1080/10298436.2012.715644

[13] Alaa, H.; Al-Azzawi, A. A. A. 2012. Evaluation of rutting depth in flexible pavements by using finite element analysis and local empirical model, American Journal of Engineering and Applied Sciences 5 (2): 163-169. http://dx.doi.org/10.3844/ajeassp.2012.163.169

[14] Karkowski, M.; Rafalski, L. 2013. The problem of overloaded vehicles in Poland, in The XXVIII International Baltic Road Conference, 8 p.

[15] Chang, J. R.; Su, Y. S.; Huang, T. C.; Kang, S. C.; Hsieh, S. H. 2009. Measurement of the International Roughness Index (IRI) Using an Autonomous Robot (P3-AT), in The 26th International Symposium on Automation and Robotics in Construction (ISARC 2009) 24-27 June 2009, Austin, Texas, $325-331$.

[16] Harris, D. 2013. Development of Methods and Specifications for the Use of Inertial Profilers and the International Roughness Index for Newly Constructed Pavement. Publication. Joint Transportation Research Program, Indiana Department of Transportation and Purdue University, West Lafayette, Indiana, 2013 (09). http://dx.doi.org/10.5703/1288284315211

[17] Khattak, J. M.; Nur, M. A.; Bhuyan, M. R. U. K.; Gaspard, K. 2013. International roughness index models for HMA overlay treatment of flexible and composite pavements, International Journal of Pavement Engineering. http://dx.doi.org/10.1080/10298436.2013.842237

[18] Sandra, A. K.; Sarkar, A. K., 2012. Development of a model for estimating International Roughness Index from pavement distresses, International Journal of Pavement Engineering 14 (8): 715-724. http://dx. doi.org/10.1080/10298436.2012.703322

[19] Ma, T.; Huang, X.; Zhao, Y.; Yuan, H.; Ma, X. 2012. Degradation Behavior and Mechanism of HMA Aggregate, Journal of Testing and Evaluation 40(5): 697-707. http://dx.doi.org/10.1520/JTE20120057 